\title{
KB425796-A, a novel antifungal antibiotic produced by Paenibacillus sp. 530603
}

\author{
Hirohito Kai ${ }^{1}$, Midori Yamashita ${ }^{1}$, Shigehiro Takase ${ }^{1}$, Michizane Hashimoto ${ }^{2}$, Hideyuki Muramatsu ${ }^{2}$, \\ Ikuko Nakamura $^{1}$, Koji Yoshikawa ${ }^{1}$, Masami Ezaki ${ }^{1}$, Kumiko Nitta ${ }^{1}$, Masato Watanabe ${ }^{1}$, \\ Noriaki Inamura ${ }^{1}$ and Akihiko Fujie ${ }^{1}$
}

The novel antifungal macrocyclic lipopeptidolactone, KB425796-A (1), was isolated from the fermentation broth of bacterial strain 530603, which was identified as a new Paenibacillus species based on morphological and physiological characteristics, and 16S rRNA sequences. KB425796-A (1) was isolated as white powder by solvent extraction, HP-20 and ODS-B column chromatography, and lyophilization, and was determined to have the molecular formula $\mathrm{C}_{79} \mathrm{H}_{115} \mathrm{~N}_{19} \mathrm{O}_{18}$. $\mathrm{KB} 425796-\mathrm{A}$ (1) showed antifungal activities against Aspergillus fumigatus and the micafungin-resistant infectious fungi Trichosporon asahii, Rhizopus oryzae, Pseudallescheria boydii and Cryptococcus neoformans.

The Journal of Antibiotics (2013) 66, 465-471; doi:10.1038/ja.2013.63; published online 19 June 2013

Keywords: antifungal; fermentation; isolation; KB425796-A; Paenibacillus sp

\section{INTRODUCTION}

Life-threatening infections caused by Aspergillus fumigatus are increasing in prevalence, particularly in immunocompromised and neutropic patients. ${ }^{1}$ However, antifungal therapies are currently limited to a small number of compounds. For example, toxicity is an issue for treatments based on amphotericin B, and a high potential for drugdrug interactions has been reported between azoles and anticancer agents or immunosuppressants, and causes difficulty in clinical use. ${ }^{2}$ Thus, a need exists for effective novel antifungal compounds that are easy to use in clinical practice.

The fungal cell wall, which is composed of $\beta$-glucan, chitin and mannan, is essential to fungi and is fundamentally different from mammalian cell wall, making it an ideal target for antifungal drugs. In particular, $1,3-\beta$-glucan is a promising antifungal target, which is an essential structural component of chytridiomycetes, ascomycetes, basidiomycetes and deuteromycetes. ${ }^{3}$ In recent years, three new antifungal drugs, micafungin, ${ }^{4,5}$ caspofungin ${ }^{6}$ and anidulafungin, ${ }^{7}$ which inhibit fungal 1,3- $\beta$-glucan synthase, have been launched; however, these drugs are fungistatic against $A$. fumigatus and have limited efficacy. ${ }^{8}$

In a course of searching for inhibitors of fungal cell wall synthesis from microorganisms, we isolated the novel lipopeptide KB425796-A (1) from the cultured broth of Paenibacillus sp. 530603. KB425796-A (1) is a 40-membered macrocyclic lipopeptidolactone consisting of 12 amino acids and a 3-hydroxy-13-methylmyristoyl moiety (Figure 1). In the present paper, we studied the taxonomy of the KB425796-Aproducing strain, the fermentation, isolation, physicochemical properties, structure and preliminary biological properties of KB425796-A (1).

\section{RESULTS}

Taxonomic study

The cultural and physiological characteristics of strain 530603 are summarized in Table 1. Strain No. 530603 was a Gram-positive motile bacterium and had a temperature range for growth of $10-45^{\circ} \mathrm{C}$, with an optimum between $30-35^{\circ} \mathrm{C}$. Strain 530603 gave positive results for oxidase and catalase, and acid production from glucose and arabinose. Colonies on Luria-Bertani (LB) agar medium grew rapidly and were translucent, mucous and convex with a diameter of $\sim 7 \mathrm{~mm}$ after 3 days of culture. Microscopic observation showed rod-shaped, single or short chains of cells $(0.5-0.8 \times 2.5-15 \mu \mathrm{m})$. Oval endospores $(0.5-1.2 \times 1.5-2.5 \mu \mathrm{m})$ were located terminally within swollen sporulating cells. The $16 \mathrm{~S}$ ribosomal RNA gene sequence of strain 530603 determined in this study was almost complete, comprising 1502 nucleotides (nt) and having $>99 \%$ similarity with those of Paenibacillus species. The phylogenetic tree constructed by the neighbor-joining method on the basis of almost-complete $16 \mathrm{~S}$ rRNA gene sequences showed the relationship between strain 530603 and closely related valid species of the genus Paenibacillus (Figure 2). The morphological and physiological characteristics of strain 530603 were also highly similar to those of Paenibacillus species.

The 16S rRNA gene sequence of strain 530603 showed the highest similarity $(99.85 \%)$ to that of Paenibacillus dendritiformis. Thus, to determine the species of strain 530603, cells of this strain were compared with $P$. dendritriformis T168T (BGSC 30A1). ${ }^{9}$ Several differences were detected between the two strains: tip-splitting colony morphology, cell size, spore position, salt tolerance and acid

${ }^{1}$ Drug Discovery Research, Astellas Pharma Inc., Tsukuba-shi, Ibaraki, Japan and ${ }^{2}$ Fermentation Research Division, Astellas Research Technologies Co., Ltd., Tsukuba-shi, Ibaraki, Japan

Correspondence: H Kai, Drug Discovery Research, Astellas Pharma Inc., 21 Miyukigaoka, Tsukuba-shi, Ibaraki 305-8585, Japan.

E-mail: hirohito.kai@astellas.com

Received 5 December 2012; revised 26 March 2013; accepted 2 April 2013; published online 19 June 2013 


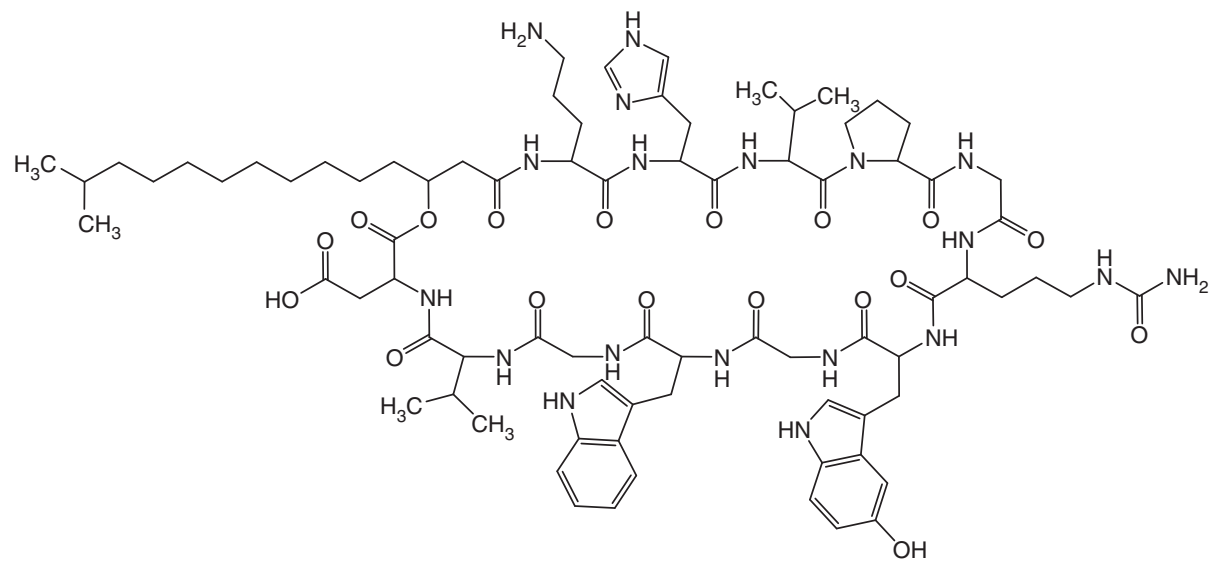

Figure 1 Chemical structure of KB425796-A (1).

Table 1 Comparison of strain 530603 and Paenibacillus dendritriformis $\mathrm{T} 168 \mathrm{~T}$

\begin{tabular}{|c|c|c|}
\hline Characteristic & strain 530603 & $\begin{array}{c}\text { P. dendritriformis } \\
\text { T168T }\end{array}$ \\
\hline Cell size $(\mu \mathrm{m})$ & $\begin{array}{c}0.5-0.8 \text { by } 2.5- \\
15\end{array}$ & $0.5-1.0$ by $2.0-3.0$ \\
\hline $\begin{array}{l}\text { Branch pattern formation on peptone } \\
\text { agar }\end{array}$ & - & + \\
\hline Spore shape & oval & oval \\
\hline Spore position & terminal & $\begin{array}{l}\text { subterminal of } \\
\text { terminal }\end{array}$ \\
\hline Swollen sporangia & + & + \\
\hline Anaerobic growth & + & + \\
\hline Catalase & + & + \\
\hline Oxidase & + & + \\
\hline \multicolumn{3}{|l|}{ Production of: } \\
\hline Indole & - & + \\
\hline Voges-Proskauer test & - & + \\
\hline \multicolumn{3}{|l|}{ Hydrolysis of: } \\
\hline Casein & + & + \\
\hline Starch & + & + \\
\hline \multicolumn{3}{|l|}{ Acid production from: } \\
\hline Glucose & + & + \\
\hline Arabinose & + & + \\
\hline Mannitol & - & - \\
\hline Xylose & - & - \\
\hline $45^{\circ} \mathrm{C}$ & + & + \\
\hline $65^{\circ} \mathrm{C}$ & - & - \\
\hline $\mathrm{pH} 5.7$ & + & + \\
\hline $5 \% \mathrm{NaCl}$ & + & + \\
\hline $7 \% \mathrm{NaCl}$ & - & + \\
\hline \multicolumn{3}{|l|}{$\begin{array}{l}+, \text { positive. } \\
-, \text { negative. }\end{array}$} \\
\hline \multicolumn{3}{|c|}{$\begin{array}{l}\text { production from several carbon sources (Table 1). On the basis of } \\
\text { results of the } 16 \mathrm{~S} \text { rRNA gene and phenotypic analyses, we considered } \\
\text { that strain } 530603 \text { belongs to the genus Paenibacillus. Further study } \\
\text { will be needed to determine the species of this strain, though there is a } \\
\text { possibility that this strain belongs to a new species of the genus } \\
\text { Paenibacillus. This strain has been deposited at the National Institute } \\
\text { of Advanced Industrial Science and Technology, Japan, as FERM BP- } \\
10803 \text {, and the GenBank/EMBL/DDBJ with the accession number for } \\
\text { the } 16 \mathrm{~S} \text { rRNA gene sequence of strain } 530603 \text { being AB746175. }\end{array}$} \\
\hline
\end{tabular}

Isolation and purification of KB425796-A (1)

KB425796-A was isolated from the culture broth of Paenibacillus sp. 530603 using the following procedure. First, an equal volume of acetone was added to the culture broth and the resulting mixture was filtered through diatomaceous earth. The filtrate was diluted with an equal volume of water and passed through a DIAION HP-20 column (5.0 l; Mitsubishi Chemical Co., Ltd., Tokyo, Japan) packed with water. The column was washed with water (15l) and 50\% aqueous methanol (15l), and eluted with methanol (17l). The active fraction (0-151) was diluted with an equal volume of water and then loaded into a Daisogel SP-120-ODS-B column $(15 / 30 \mu \mathrm{m}, 2$ l; Daiso Co., Ltd., Osaka, Japan) packed with water. The column was washed with water (5l) and eluted with $45 \%$ aqueous acetonitrile containing $0.1 \%$ TFA (4.51). The active fraction $(0.5-4.01)$ was diluted with an equal volume of water and then loaded into a Daisogel SP-120-ODSB column $(15 / 30 \mu \mathrm{m}, 21$; Daiso Co., Ltd.) packed with water. The column was washed with water (51) and eluted with $42 \%$ aqueous acetonitrile containing $0.1 \%$ TFA (4l). The active fraction (2-31) was diluted with an equal volume of water and then loaded into a Daisogel SP-120-ODS-B column (15/30 $\mu \mathrm{m}$, Daiso Co., Ltd.) packed with water. The column was washed with water (5l) and eluted with $40 \%$ aqueous acetonitrile containing $0.1 \%$ TFA (51). The active fraction (1.5-3.5 l) was diluted with an equal volume of water and then loaded into a Daisogel SP-120-ODS-B column $(15 / 30 \mu \mathrm{m}, 0.2 \mathrm{l}$; Daiso Co., Ltd.) packed with water. The column was washed with water (11) and eluted with methanol (0.21).

The active fraction was concentrated in vacuo to an aqueous solution and lyophilized to yield $1.62 \mathrm{~g}$ of crude powder KB425796-A (1). The powder was dissolved in $2 \mathrm{ml}$ methanol and applied to the top of a silica gel 60 column $(40 / 50 \mu \mathrm{m}, 50 \mathrm{ml}$; Kanto Chemical Co., Ltd., Tokyo, Japan) packed with chloroform. The column was eluted with a mixture of chloroform-methanol $(10: 1,150 \mathrm{ml})$, and fractions containing KB425796-A (1) were collected and dried to give $1.50 \mathrm{~g}$ of white powder KB425796-A (1).

\section{Physicochemical properties and structural elucidation of KB425796-A (1)}

The physicochemical properties of KB425796-A (1) are summarized in Table 2. KB425796-A (1) was soluble in methanol and dimethyl sulfoxide, sparingly soluble in chloroform and acetone, and insoluble in water and ethyl acetate. KB425796-A (1) displayed positive color reactions to iodine vapor, ceric sulfate and ninhydrin, but had negative color reactions to Molish, Dragendorff and ferric chloride. 


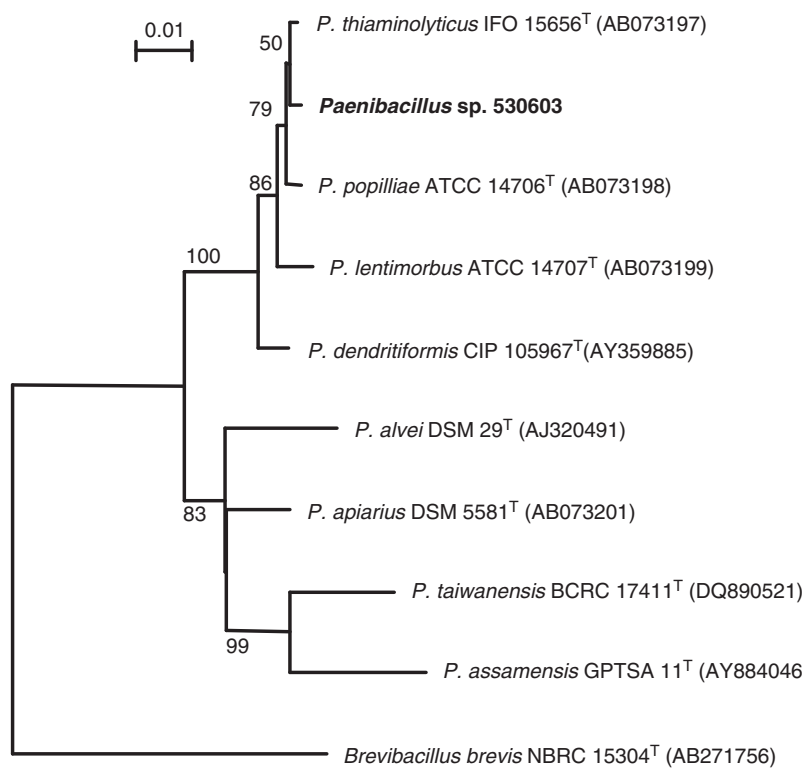

Figure 2 Neighbor-joining phylogenetic tree on the basis of almost-complete 16S rRNA gene sequences showing the relationship between strain 530603 and closely related valid species of the genus Paenibacillus. Bootstrap value $(>50 \%)$ on the basis of 1000 replicates are shown at branch nodes. Bar, 0.01 substitutions per nucleotide position.

The UV absorption maxima of purified KB425796-A (1) occurred at 280 and $290 \mathrm{~nm}$, and a molecular ion peak at $m / z 1619\left([\mathrm{M}+\mathrm{H}]^{+}\right)$ was detected in the ESI-MS spectrum (data not shown).

The exact molecular mass of KB425796-A (1) (founded by ESITOF-MS) was $1618.8745 \mathrm{Da}\left([\mathrm{M}+\mathrm{H}]^{+}\right)$and $1616.8600 \mathrm{Da}([\mathrm{M}-$ $\left.\mathrm{H}^{-}\right)$), which corresponded to the molecular formula $\mathrm{C}_{79} \mathrm{H}_{115} \mathrm{~N}_{19} \mathrm{O}_{18}$ (theoretical: $[\mathrm{M}+\mathrm{H}]^{+} 1618.8740 \mathrm{Da}$ and $[\mathrm{M}-\mathrm{H}]^{-} 1616.8595 \mathrm{Da}$ ) and was consistent with the NMR data (Table 3 and Supplementary Information).

The preparation of KB425796-A (1) contained several structurally related minor congeners. The use of DMSO- $\mathrm{d}_{6}$ was avoided in the NMR measurement because of the difficulty of recovering material for bioassays. The ${ }^{1} \mathrm{H}$ NMR spectra measured in $\mathrm{CD}_{3} \mathrm{OD}$ displayed sharp and well-resolved signals. As an amide $\mathrm{NH}$ proton was useful in assigning the sequence of a target peptide, $\mathrm{CD}_{3} \mathrm{OH}$ was also employed for a series of NMR spectra.

The structural assignments of the standard amino acids, (Orn $(\boldsymbol{a})$, His $(\boldsymbol{b})$, Val $(\boldsymbol{c})$, Pro $(\boldsymbol{d})$, Gly $(\boldsymbol{e})$, Gly $(\boldsymbol{h})$, Trp $(\boldsymbol{i})$, Gly $(\boldsymbol{j})$, Val $(\boldsymbol{k})$ and Asp $(\boldsymbol{l})$ ), as shown in Figure 3, were made without difficulty. In addition, analysis of the NMR data, using $1 \mathrm{D}\left({ }^{1} \mathrm{H},{ }^{13} \mathrm{C}\right.$ and DEPT) and 2D (COSY, TOCSY, HSQC, HMBC and ROESY) techniques, revealed the presence of two uncommon non-proteinogenic amino acids, citrulline (Cit $(\boldsymbol{f}))$ and 5-hydroxytryptophan (HOTrp $(\boldsymbol{g}))$, and an acyl component $(\boldsymbol{m})$ (Figure 3 ). Cit $(\boldsymbol{f})$ : the COSY and TOCSY experiments indicated that $\mathbf{1}$ possessed a spin system similar to Orn. The terminal nitrogen-bearing methylene protons $\left(\delta_{\mathrm{H}} 2.90\right.$ and 2.84) showed HMBC correlations with a carbonyl group $\left(\delta_{\mathrm{C}} 162.3\right)$, reminiscent of an ureido group. The presence of an ureido group was further supported from ROE correlation between $-\mathrm{NH}_{2}\left(\delta_{\mathrm{H}} 5.45\right.$ $(2 \mathrm{H}$, br s $))$ and $-\mathrm{NH}\left(\delta_{\mathrm{H}} 5.90(1 \mathrm{H}, \mathrm{br} \mathrm{t})\right)$. The presence of the ureido group and Orn-like residue identified the subunit $(f)$ as a citrulline residue. HOTrp $(g)$ : the low-field shifted NH signal at 10.13 p.p.m. was due to Trp indole-NH (i). Another low-field NH signal at 10.08 p.p.m. was indicative of a Trp-like residue. The three benzene proton
Table 2 Physicochemical properties of KB425796-A(1)

\begin{tabular}{|c|c|}
\hline $\begin{array}{l}\text { Appearance } \\
\text { Specific rotation }\end{array}$ & White powder \\
\hline \multicolumn{2}{|l|}{$[\alpha]_{D}^{23}$} \\
\hline \multicolumn{2}{|l|}{ HR-LC-MS $(m / z)$} \\
\hline Found $(m / z)$ & $1618.8745[\mathrm{M}+\mathrm{H}]^{+}, 1616.8600[\mathrm{M}-\mathrm{H}]^{-}$ \\
\hline Calcd $(m / z)$ & $1618.8740[\mathrm{M}+\mathrm{H}]^{+}, 1616.8595[\mathrm{M}-\mathrm{H}]^{-}$ \\
\hline Molecular formula & $\mathrm{C}_{79} \mathrm{H}_{115} \mathrm{~N}_{19} \mathrm{O}_{18}$ \\
\hline UV $\lambda_{\max }^{\mathrm{MeOH}} \mathrm{nm}(\varepsilon)$ & $290(10700), 280(12900)$ \\
\hline \multicolumn{2}{|l|}{ Color test } \\
\hline Positive & $\mathrm{I}_{2}, \mathrm{Ce}\left(\mathrm{SO}_{4}\right)_{2}-\mathrm{H}_{2} \mathrm{SO}_{4}$, Ninhydrin \\
\hline Negative & Molish, Dragendorff, $\mathrm{FeCl}_{3}$ \\
\hline \multicolumn{2}{|l|}{ Solubility } \\
\hline Soluble & methanol, DMSO \\
\hline Insoluble & $\mathrm{H}_{2} \mathrm{O}$, ethyl acetate \\
\hline $\mathrm{IR} \lambda_{\max }(\mathrm{KBr}) \mathrm{cm}^{-1}$ & $\begin{array}{l}3300,2930,2860,2360,1650,1540,1460,1400, \\
1200\end{array}$ \\
\hline TLC (Rf value) $)^{a}$ & 0.45 \\
\hline
\end{tabular}

asilica gel 60 NH2 F254s (MERCK):methanol-chloroform (1:1).

signals $\left(\delta_{\mathrm{H}} 7.18(\mathrm{~d}, J=8.5 \mathrm{~Hz}), 7.03(\mathrm{~d}, J=1.5 \mathrm{~Hz})\right.$, and $6.78(\mathrm{dd}$, $J=8.5$ and $1.5 \mathrm{~Hz}$ )) suggested that the residue was 5-hydroxytryptophan or 6-hydroxytryptophan. ROE correlation between $\beta-\mathrm{CH}_{2}\left(\delta_{\mathrm{H}}\right.$ $3.47)$ and the benzene signal $\left(\delta_{\mathrm{H}} 7.03\right)$ identified the subunit $(g)$ as 5-hydroxytryptophan. Acyl component (m): 2-methylpropyl and 3-hydroxybutyryl units were evident from the COSY, HSQC and HMBC analyses. Seven aliphatic methylene resonances around $\delta_{\mathrm{H}}$ $1.30-1.20\left(\delta_{\mathrm{C}} 30.9(\mathrm{t}), 30.7(\mathrm{t}), 30.6(\mathrm{t}), 30.5(\mathrm{t}), 30.4(\mathrm{t}), 28.5(\mathrm{t})\right.$, and $27.0(\mathrm{t}))$, together with the identified 2-methylpropyl and 3-hydroxybutyryl units indicated the presence of a 3-hydroxy-13-methylmyristoyl moiety $(\boldsymbol{m})$. The 12 amino acids and acyl component accounted for all of the atoms present in $\mathbf{1}$ and for 31 out of the 32 degrees of unsaturation required by the molecular formula. The remaining unsaturation was due to the cyclic nature of 1 .

Subunits $\boldsymbol{a} \sim \boldsymbol{m}$ were assembled into two fragments, $\operatorname{acyl}(\boldsymbol{m})$ $\operatorname{Orn}(\boldsymbol{a})-\mathrm{His}(\boldsymbol{b})-\mathrm{Val}(\boldsymbol{c})-$ and $-\mathrm{Gly}(\boldsymbol{e})-\mathrm{Cit}(\boldsymbol{f})-\mathrm{OHTrp}(\boldsymbol{g})-\mathrm{Gly}(\boldsymbol{h})-\operatorname{Trp}(\boldsymbol{i})-$ $\operatorname{Gly}(\boldsymbol{j})-\operatorname{Val}(\boldsymbol{k})-\operatorname{Asp}(\boldsymbol{l})$ - by extensive consideration of the HMBC correlations (Figure 4). These proposed sequences were further supported by the ROE results (Figure 4). Additionally, ROE connectivities between $\operatorname{Val}(\boldsymbol{c}) \alpha \mathrm{H}\left(\delta_{\mathrm{H}} 4.30\right)$ and $\operatorname{Pro}(\boldsymbol{d}) \delta-\mathrm{CH}_{2}\left(\delta_{\mathrm{H}} 3.60\right)$, and between $\operatorname{Pro}(\boldsymbol{d})$ $\alpha \mathrm{H}\left(\delta_{\mathrm{H}} 4.32\right)$ and $\mathrm{Gly}(\boldsymbol{e}) \mathrm{NH}\left(\delta_{\mathrm{H}} 7.33\right)$ indicated the presence of a $\operatorname{Val}(\boldsymbol{c})-\operatorname{Pro}(\boldsymbol{d})-\mathrm{Gly}(\boldsymbol{e})$ fragment. The ROE results allowed us to connect the identified fragments to assemble the gross sequence of 1 . The ${ }^{1} \mathrm{H}$ and ${ }^{13} \mathrm{C}$ chemical shifts $\left(\delta_{\mathrm{H}} 5.08, \delta_{\mathrm{C}} 72.8\right)$ of C-3 in subunit $(\boldsymbol{m})$ were characteristic of an acyloxymethine. Macrocyclic lactone was indicated by the HMBC correlation from $\mathrm{H}-3(\boldsymbol{m})$ to $\operatorname{Asp}(\boldsymbol{l})$ carbonyl. On the basis of the above described analyses, the structure of KB425796-A was elucidated to be 1, as depicted in Figure 1.

\section{Biological activity}

The antifungal activity of KB425796-A (1) against several fungi is shown in Table 4. KB425796-A (1) exhibited potent antifungal activity against $A$. fumigatus and a variety of micafungin-resistant fungal species Trichosporon asahii, Rhizopus oryzae, Pseudallescheria boydii and Cryptococcus neoformans, with particularly high efficiency against $T$. asahii, but was inactive against Candida albicans. Microscopic observation of A. fumigatus cells after treatment with KB425796-A (1) revealed several morphological changes, including swelling and bulging of hyphae (Figure 5a), in comparison with the 
Table $3{ }^{1} \mathrm{H}(500 \mathrm{MHz})$ and ${ }^{13} \mathrm{C}(125 \mathrm{MHz})$ NMR assignments of WB425796A

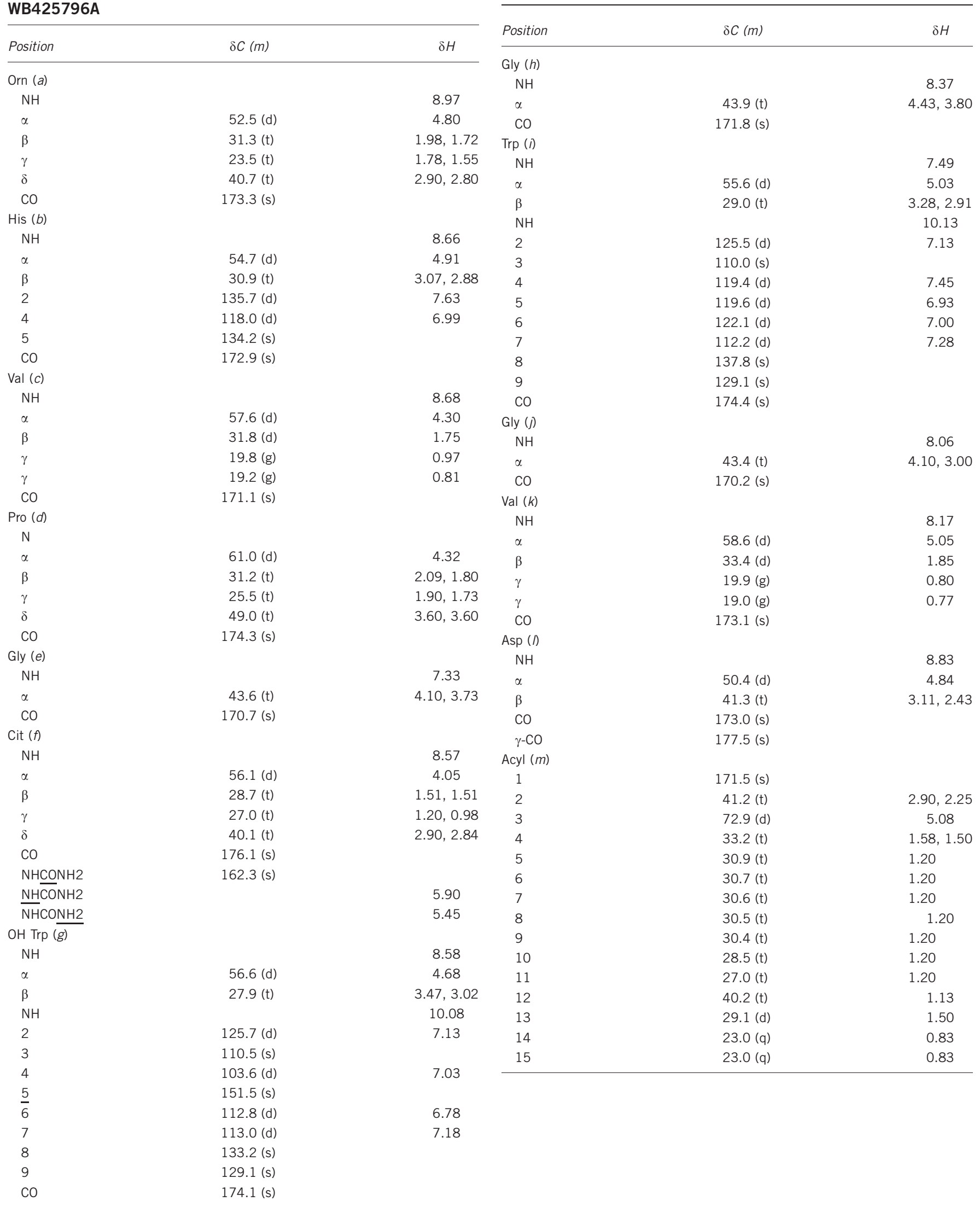

Table 3 (Continued) 


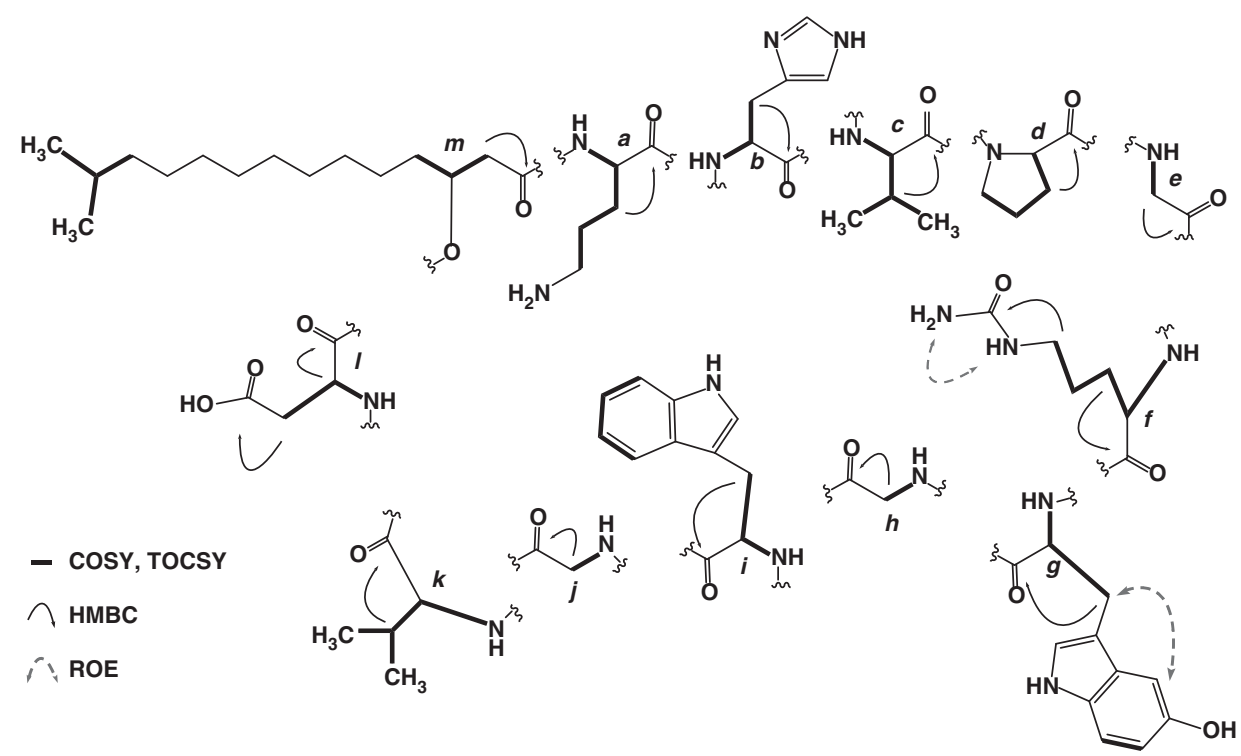

Figure 3 Subunits $\mathbf{a}-\boldsymbol{m}$ of $\mathbf{1}$. A full color version of this figure is available at The Journal of Antibiotics journal online.

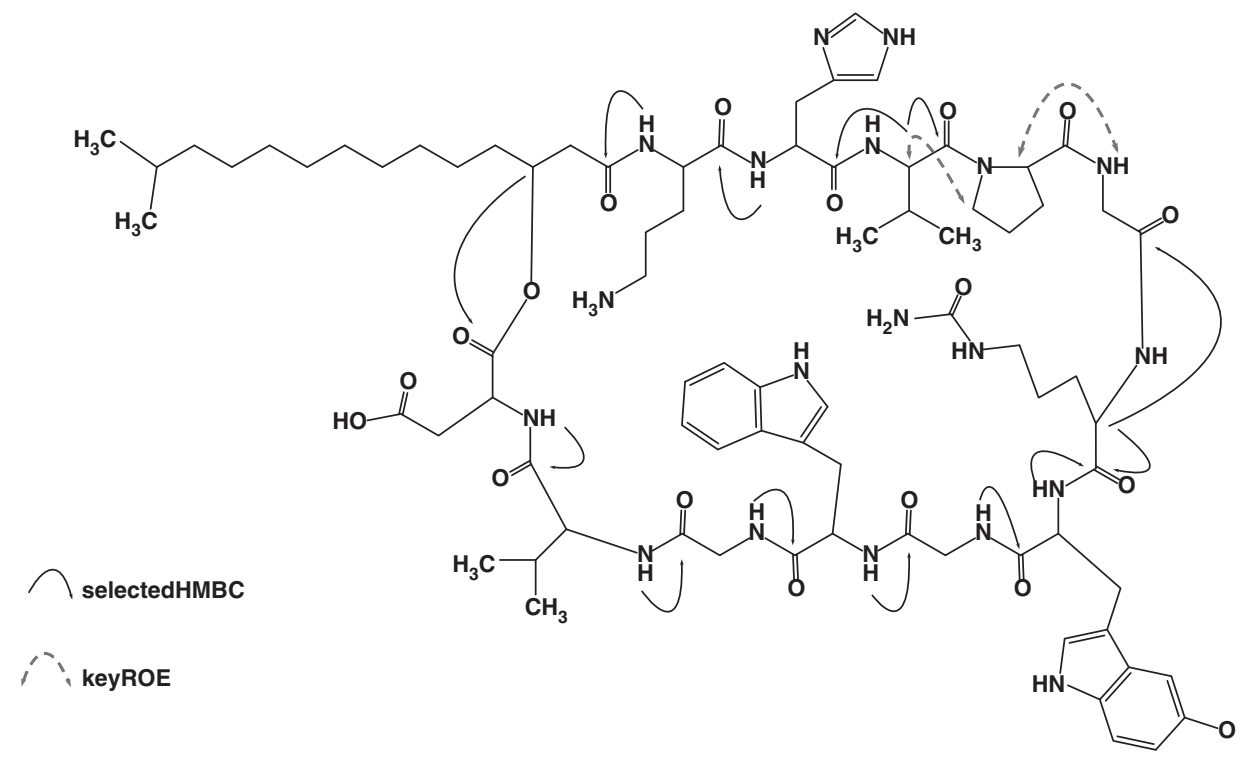

Figure 4 Key HMBC and ROE for the sequence analysis of 1. A full color version of this figure is available at The Journal of Antibiotics journal online.

micafungin-treated hyphae (Figure 5b) and untreated control hyphae (Figure 5c). The cytotoxicity ( $\mathrm{IC}_{50}$ ) of KB425796-A (1) for EL-4 cells was $>50 \mu \mathrm{g} \mathrm{ml}^{-1}$.

\section{DISCUSSION}

In this paper, we have presented the isolation and characterization of the novel antifungal lipopeptide, KB425796-A, isolated from the fermentation broth of a soil isolate (530603), which was determined to be a species of Paenibacillus based on morphological and physiological characterization. The $16 \mathrm{~S}$ rRNA gene sequence indicated that strain 530603 was closely affiliated with $P$. dendritiformus, although a few phenotypic differences were detected between the type strain T168T and strain 530603. Based on these analyses, we concluded that strain 530603 is a novel species within the genus Paenibacillus. We identified the novel antifungal compound
Table 4 Antifungal activity of KB425796-A (1) and micafungin

\begin{tabular}{lcc}
\hline & \multicolumn{2}{c}{$M E C\left(\mu g \mathrm{ml}^{-1}\right)$} \\
\cline { 2 - 3 } Test organism & KB425796-A & micafungin \\
\hline Aspergillus fumigatus FP1305 & 6.25 & 0.05 \\
Candida albicans FP633 & $>50$ & 0.01 \\
Cryptococcus neoformans YC203 & 3.13 & $>50$ \\
Trichosporon asahii FP2044 & 1.56 & 50 \\
Rhizopus oryzae FP1988 & 3.13 & 50 \\
Pseudallescheria boydii FP1987 & 6.25 & $>50$ \\
\hline
\end{tabular}

KB425796-A (1) in the culture broth of strain No. 530603 and demonstrated that this compound had strong activity against A. fumigatus. 

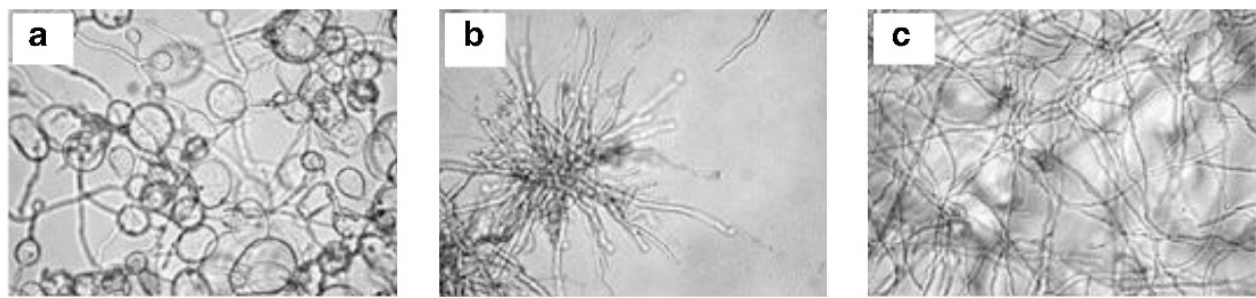

Figure 5 Hyphal morphology of $A$. fumigatus after treatment with KB425796-A (1) and micafungin. (a) $6.25 \mu g \mathrm{ml}^{-1} \mathrm{~KB}^{-} 25796-\mathrm{A}$, (b) $0.05 \mu \mathrm{gm}-1$ micafungin and (c) control. Scale bar, $100 \mu \mathrm{m}$. A full color version of this figure is available at The Journal of Antibiotics journal online.

Among microbial secondary metabolites characterized to date, two 40-membered macrocyclic lipopeptidolactones consisting of 12 amino acids have been identified: WAP-8294 (Tcherpakov et al. ${ }^{9}$ ) and FR901469. ${ }^{10,11}$ WAP-8294 was discovered as an anti-methicillinresistant Staphylococcus aureus (MRSA) agent but did not exhibit antifungal activity, whereas FR901469 was a 1,3- $\beta$-glucan synthase inhibitor that was produced by fungal strain 11243. Similar to micafungin, which has 1,3- $\beta$-glucan synthase inhibitory activity, FR901469 induces the formation of short, stubby and highly branched hyphae in the infectious fungus $A$. fumigatus. ${ }^{10,12}$ In contrast to the actions of these agents, KB425796-A (1) induced swelling and bulging of $A$. fumigatus hyphae (Figure 5a), suggesting that KB425796-A (1) has a different mode of action from that of FR901469. In addition, KB425796-A (1) had antifungal activities against the micafungin-resistant infectious fungi T. asahii, $R$. oryzae, $P$. boydii and $C$. neoformans. Although the effectiveness of micafungin against infection by species of Candida and Aspergillus has been established, ${ }^{13}$ micafungin-resistant fungi remain a problematic issue in clinical practice. ${ }^{14,15}$ Although being preliminary, our present findings suggest that KB425796-A (1) has the potential utility to treat infections caused by these fungi. To investigate the efficacy of KB425796-A (1) against micafungin-resistant fungi, further antifungal studies with an in vivo infection model will be needed.

We also identified numerous possible congeners of KB425796-A by HPLC analysis of the fermentation broth of strain 530603. As these congeners may also possess potent antifungal activity, isolation and antifungal studies of these compounds will be reported in a succeeding paper.

\section{METHODS}

\section{Taxonomic Studies}

Strain 530603 was originally isolated from a soil sample collected in Aomori Prefecture, Japan. Taxonomic studies were performed based on the methods described in Bergey's manual. ${ }^{16} 16 \mathrm{~S}$ rRNA gene sequences were analyzed according to the method of Muramatsu et al. ${ }^{17}$ Phylogenic tree was generated by the neighbor-joining method based on the 16S rRNA gene sequences. Morphological observation was carried out using a light microscope with cells cultured on agar (Invitrogen Japan, Tokyo, Japan) for 3 days at $30^{\circ} \mathrm{C}$. Enzyme and carbohydrate acid production were detected using the API 50 CHB kit (BioMéruex, Lyon, France). Growth at various temperatures $\left(5-50{ }^{\circ} \mathrm{C}\right)$ was evaluated on $\mathrm{LB}$ agar.

\section{Fermentation}

Culture medium $(100 \mathrm{ml})$ consisting of $2 \%$ nutrient broth (Kyokuto, Tokyo, Japan) and $0.1 \%$ sodium pyruvate (Nacalai Tesque, Kyoto, Japan) was sterilized in $500 \mathrm{ml}$ Erlenmeyer flasks at $120^{\circ} \mathrm{C}$ for $30 \mathrm{~min}$. After cooling, the culture medium was inoculated with a loopful of cells from a slant culture of strain 530603 and incubated at $30^{\circ} \mathrm{C}$ for $48 \mathrm{~h}$ on a rotary shaker $(250$ r.p.m., $5.1-\mathrm{cm}$ throw). The resultant seed culture was inoculated into a 301 stainless steel jarfermentor containing 201 of a production medium consisting of 3\% MS3600 (Nihon Shokuhin Kako, Tokyo, Japan), 2\% peptone (Kyokuto), 1\% CSL (Nihon Shokuhin Kako), 0.05\% Adekanol defoaming agent (Asahi Denka Co.,
Ltd., Tokyo, Japan), and 0.05\% Silicone KM-70 defoaming agent (Shin-Etsu Chemical Co., Ltd., Tokyo, Japan). The fermentation was carried out at $30^{\circ} \mathrm{C}$ for 4 days under aeration at $201 \mathrm{~min}^{-1}$, an inner pressure of $1.0 \mathrm{~kg} \mathrm{~cm}^{-2}$, and agitation at 200 r.p.m.

\section{HPLC analysis}

Detection of KB425796-A (1) in the fermentation broth and column fractions during purification was performed by HPLC using a reverse phase column (L-column ODS, $250 \mathrm{~mm} \phi \times 4.6 \mathrm{~mm}$ I.D.; Chemical Evaluation and Research Institute, Japan). An aqueous acetonitrile solution (42\%) containing $0.1 \%$ TFA was used as the mobile phase at a flow rate of $1.0 \mathrm{ml} / \mathrm{min}$. The detection wavelength was set at $210 \mathrm{~nm}$.

\section{General experimental procedures}

High-resolution mass spectra were measured using a LCMS-IT-TOF spectrometer (Shimadzu, Kyoto, Japan), and UV/Vis spectra were recorded on a UV2500 PC (Shimadzu). Optical rotations were measured on a SEPA-500 polarimeter (Horiba, Kyoto, Japan). Infrared spectra were recorded with a Spectrum 65 FT-IR spectrometer (PerkinElmer). NMR spectra, ${ }^{1} \mathrm{H}(500 \mathrm{MHz})$ and ${ }^{13} \mathrm{C}(125 \mathrm{MHz})$, were recorded on an AVANCE 500 spectrometer (Bruker Japan, Yokohama, Japan) equipped with a cryoprobe. Chemical shifts were given in $\delta$ (p.p.m.) with the residual $\mathrm{CD}_{3} \mathrm{OH}$ solvent signal referenced to $\delta_{\mathrm{H}}$ 3.31 and $\delta_{\mathrm{C}} 49.15$ as the internal reference.

\section{Antimicrobial activity}

C. albicans FP633, T. asahii FP2044, R. oryzae FP1988 and P. boydii FP1987, which are clinical isolates deposited in our laboratory, ${ }^{18}$ were grown in yeastmaltose (YM) agar broth for $24 \mathrm{~h}$ at $30^{\circ} \mathrm{C}$ under the standing condition. C. neoformans YC203 (deposited in our laboratory) was cultured in YM broth for $20 \mathrm{~h}$ at $30^{\circ} \mathrm{C}$ with shaking at 250 r.p.m. A cell suspension was prepared by washing the cultured cells once with sterile saline. A. fumigatus FP1305 (deposited in our laboratory) was cultured on a potato dextrose agar (PDA) slant for 4 days at $37^{\circ} \mathrm{C}$, and spores were then harvested in sterile saline and filtered through gauze. The antifungal activity of KB425796-A (1) was measured by the micro-broth dilution method using 96-well culture plates and RPMI 1640 medium (Invitrogen) lacking sodium bicarbonate and supplemented with L-glutamine, buffered to $\mathrm{pH} 7.0$ with $0.165 \mathrm{M}$ MOPS Yeast nitrogen base-glucose (YNBD) medium was used for measuring the antifungal activity of KB425796-A (1) against C. neoformans. For the measurements, the test fungus was inoculated into each well at a final concentration of $1 \times 10^{5}$ c.f.u. per well. The plates were incubated for $20 \mathrm{~h}$ (C. albicans FP633, T. asahii FP2044, R. oryzae FP1988, P. boydii FP1987 and A. fumigatus $\mathrm{FP1305}$ ) at $37^{\circ} \mathrm{C}$ or $48 \mathrm{~h}$ (C. neoformans YC203) at $37^{\circ} \mathrm{C}$. Minimum effective concentration (MEC), which was the lowest concentration causing a substantial reduction in fungal growth, was determined by microscopic observation. ${ }^{19}$

\section{Cell cytotoxicity assay}

Cytotoxicity was examined using EL-4 cells. After 3 days of incubation with a range of KB425796-A (1) concentrations, cell viability was determined colorimetrically at $550 \mathrm{~nm}$, using $660 \mathrm{~nm}$ as a reference, using the methylthiazoletetrazolium (MTT) method ${ }^{20}$. Cytotoxicity is expressed as the concentration of a compound needed to reduce EL- 4 cell viability by $50 \%$. 
1 Wade, J. C. Treatment of fungal and other opportunistic infections in immunocompromised patients. Leukemia 11 (Suppl 4), S38-S39 (1997).

2 Thompson, G. R. 3rd, Cadena, J. \& Patterson, T. F. Overview of antifungal agents. Clin. Chest Med. 30, 203-215, (2009).

3 Liu, J. \& Balasubramanian, M. K. 1,3-beta-Glucan synthase: a useful target for antifungal drugs. Curr. Drug Targets 1, 159-169 (2001).

4 Tomishima, M. et al. FK463, a novel water-soluble echinocandin lipopeptide: synthesis and antifungal activity. J. Antibiot. 52, 674-676 (1999).

5 Higashiyama, Y. \& Kohno, S. Micafungin: a therapeutic review. Expert Review of Anti-infective Therapy 2, 345-355 (2004).

6 Cornely, O. A., Schmitz, K. \& Aisenbrey, S. The first echinocandin: caspofungin. Mycoses 45 (Suppl 3), 56-60 (2002).

7 Debono, M. et al. Semisynthetic chemical modification of the antifungal lipopeptide echinocandin B (ECB): structure-activity studies of the lipophilic and geometric parameters of polyarylated acyl analogs of ECB. J. Med. Chem. 38, 3271-3281 (1995).

8 Mikulska, M. \& Viscoli, C. Current role of echinocandins in the management of invasive aspergillosis. Curr. Infect. Dis. Rep. 13, 517-527 (2011).

9 Tcherpakov, M., Ben-Jacob, E. \& Gutnick, D. L. Paenibacillus dendritiformis sp. nov., proposal for a new pattern-forming species and its localization within a phylogenetic cluster. Int. J.Syst. Bacteriol. 49 (Pt 1), 239-246 (1999).

10 Fujie, A. et al. FR901469, a novel antifungal antibiotic from an unidentified fungus No.11243. I. Taxonomy, fermentation, isolation, physicochemical properties and biological properties. J. Antibiot. 53, 912-919 (2000).

11 Fujie, A. et al. FR901469, a novel antifungal antibiotic from an unidentified fungus No.11243. II. In vitro and in vivo activities. J. Antibiot. 53, 920-927 (2000).
12 Hatano, K., Morishita, Y., Nakai, T. \& Ikeda, F. Antifungal mechanism of FK463 against Candida albicans and Aspergillus fumigatus. J. Antibiot. 55, 219-222 (2002).

13 Hanadate, T. et al. Evaluation of the safety and efficacy of micafungin in Japanese patients with deep mycosis: a post-marketing survey report. J. Infect. Chemother. 17, 622-632 (2011).

14 Uchida, K., Nishiyama, Y., Yokota, N. \& Yamaguchi, H. In vitro antifungal activity of a novel lipopeptide antifungal agent, FK463, against various fungal pathogens. J. Antibiot. 53, 1175-1181 (2000).

15 Matsue, K., Uryu, H., Koseki, M., Asada, N. \& Takeuchi, M. Breakthrough trichosporonosis in patients with hematologic malignancies receiving micafungin. Clin. Infect. Dis. 42, 753-757 (2006).

16 Sneath, PHA. et al. Bergey's Manual of Systematic Bacteriology. 2nd. edn. (William \& Wilkins Co., Baltimore, MA, USA, 1986)

17 Muramatsu, H., Mokhtar, S., Katsuoka, M. \& Ezaki, M. Phylogenic analysis of immunosuppressant FK506-producing streptomycete strains. Actinomycetologica 19, 33-39 (2005).

18 Tawara, S. et al. In vitro activities of a new lipopeptide antifungal agent, FK463, against a variety of clinically important fungi. Antimicrob. Agents Chemother. 44, 57-62 (2000).

19 Kanasaki, R. et al. FR220897 and FR220899, novel antifungal lipopeptides from Coleophoma empetri no. 14573. J. Antibiot. 59, 149-157 (2006).

20 Berg, K., Hansen, M. B. \& Nielsen, S. E. A new sensitive bioassay for precise quantification of interferon activity as measured via the mitochondrial dehydrogenase function in cells (MTT-method). APMIS 98, 156-162 (1990).

Supplementary Information accompanies the paper on The Journal of Antibiotics website (http://www.nature.com/ja) 